\title{
EFFECTIVENESS OF PURSED LIP BREATHING EXERCISE ON DYSPNOEA AMONG CHRONIC OBSTRUCTIVE PULMONARY DISEASE (COPD) PATIENTS.
}

\author{
Mrs. Mani. Abhirami* | Dr. C. Nalini Jeyavantha Santha** \\ *Ph.D. Scholar, Himalayan University, Itanagar, Arunachal Pradesh, India. \\ **Guide \& Principal, Sacred Heart College of Nursing, Madurai, Tamil Nadu, India. \\ DOI: http://doi.org/10.47211/idcij.2020.v07i03.006 \\ Received $25^{\text {th }}$ May 2020, Accepted $5^{\text {th }}$ June 2020, Available online $10^{\text {th }}$ July 2020.
}

\begin{abstract}
Chronic Obstructive Pulmonary Disease is a progressive disease condition strongly associated with dyspnoea and exercise limitation in activities of daily life. So far there is no cure for this disease only effort to alleviate the symptoms. It is therefore of great importance to define effective Pursed Lip Breathing technique to relieve symptoms and to motivate patients to exercise. The objectives of the study were to assess the pre and post-test dyspnoea score among chronic obstructive pulmonary disease (COPD) patients in experimental and control groups and also to evaluate the effectiveness of pursed-lip breathing on the level of dyspnoea. Quasiexperimental design, pretest-posttest non-equivalent control group design was adopted, 160 samples were diagnosed as COPD, and falls mild to moderate dyspnea. Data collected through demographic variables and dyspnoea scores by using Modified (UCSD) the University Of California, San Diego Shortness of Breath Questionnaire. 15-items were measured while performing a variety of activities of daily living. Pursed lip breathing exercises are given in the intervention program for 5 days and the Results concluded that chronic obstructive pulmonary disease $(C O P D)$ patients in experimental group overall $p$-value score $(p<0.001)$ revealed highly significant differences in pre and post a comparison of reduction of dyspnoea score in the experimental and control group. Keywords: COPD, pursed-lip breathing exercises, dyspnoea.
\end{abstract}

Key Words: Pulmonary disease, Lip Breathing Exercise.

\section{ABOUT AUTHORS:}

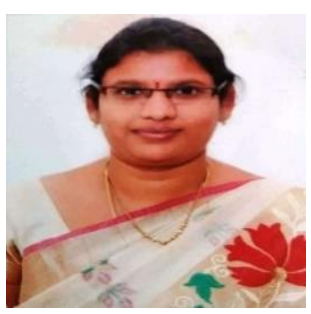

Author Mrs. M. Abhirami. Is Ph.D. Scholar at Himalayan University at Itanagar in the Indian State Of Arunachal Pradesh. She has attended various International and National conference and Organized Seminars, Workshops, Presented Papers at TNAI conference.

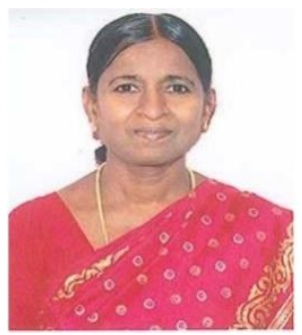

Author Dr. C. Nalini Jeyavantha Santha is working as Principal for 18 years in Sacred Heart College of Nursing, Madurai, Tamil Nadu. She is a research guide for postgraduate students and Ph.D. scholars. She has presented more than 20 papers in various National and International conferences and organized various workshops and conferences. 


\section{INTRODUCTION}

Chronic obstructive pulmonary disease (COPD) refers to the conditions of a combination of chronic bronchitis and emphysema, resulting in airway obstruction and poor oxygen transport in the lungs, respectively. It is a progressive lung disease that is not fully reversible. The hallmark of the disease is shortness of breathing that gradually gets worse over time. Dyspnoea is "a term used to characterize a subjective experience of breathing discomfort that consists of qualitatively distinct sensations that vary in intensity. Pursed Lip Breathing Exercise is one of the effective rehabilitation approaches for relaxation and easily practicable, it helps the vital balance of blood gases and also to relieve shortness of breath. Many of the populations documented the patients with Chronic Obstructive Pulmonary Disease and found that they have decreased quality of life and daily activities. Looking into the above-mentioned reason the researcher decided to conduct the study to assess the effectiveness of Pursed Lip-Breathing Exercise to improve breathing patterns and quality of life among patients with Chronic Obstructive Pulmonary Disease.

\section{NEED FOR THE STUDY}

According to the global burden of disease (GBD) in the year of 2016, a prevalence of 251 million cases of COPD has been reported globally. Nearly 65 million people have been diagnosed with a moderate to severe degree of COPD. There were 3.17 million deaths caused by this disease in 2015 (that is, $5 \%$ of all deaths globally in that year). Based on the socioeconomic status the low and middle-income countries more prevalence of deaths due to COPD which is above more than $90 \%$.this is because of higher exposure of tobacco intake and smoking (either active or passive) are the primary risk factors. In addition to that, other factors include exposure to indoor and outdoor pollution, occupational dust, and fumes (WHO2017).

Currently, there are about 98 million smokers in India and the total burden of COPD is about 14.84 million in 2011, doubled from 6.45 million in 1971 as per WHO. Management of patients with COPD, the strategy includes pharmacological and non- pharmacological approaches which include pulmonary rehabilitation occupying a vital part.

Prabhu Rajkumar et.al., (2017) conducted a cross-sectional study on the prevalence of the chronic obstructive pulmonary disease in a population of suburban areas of Chennai and shilling which represents a southern and northern region of India Prevalence of COPD is estimated that at 3.49\% in India ranging from 1.1\% in Mumbai to $10 \%$ in Thiruvananthapuram. The burden of Obstructive Lung Disease (BOLD) conducted a study in Pune, Mumbai, and Srinagar and reported overall COPD prevalence estimate of $6.25 \% 6.8 \%$ and $16.05 \%$, and identified the risk factors for COPD were smoking air pollution and important comorbid conditions chronic respiratory disorder such as asthma and post tuberculosis.

\section{PROBLEM STATEMENT:}

"Effectiveness of pursed-lip breathing exercise on dyspnoea among chronic obstructive pulmonary disease

$$
\text { (COPD) patients." }
$$

\section{OBJECTIVES:}

1. To assess the pre and post-test dyspnoea score among chronic obstructive pulmonary disease (COPD) patients in the experimental group and control group

2. To evaluate the effectiveness of pursed-lip breathing on the level of dyspnoea among chronic obstructive pulmonary disease (COPD) patients

3. To find the association between dyspnoea score and with their selected demographic variables

\section{RESEARCH METHODOLOGY}

$>$ Research approach and design: an evaluative research approach Quasi-experimental design, pretestposttest non-equivalent control group design respectively.

$>$ The setting of the study: Medicine department in PES hospital, kuppam.

> Participants: All the patients who are diagnosed as COPD and admitted in PESIMSR Kuppam.

$>$ Sample: patients who are diagnosed as COPD and fall mild to moderate dyspnoea. 


\section{ARTICLES}

Sample size: Power analysis used for sample size confirmation, N 80 in experimental, and N 80 in the control group. Total of 160 .

> Sample technique: The nonprobability convenience sampling technique was used to select samples.

\section{SAMPLING CRITERIA:}

Inclusion criteria: The COPD patients who

$>$ Falls between the age range of 30-70year

Exclusive criteria:

$>$ Have mild to moderate degree of dyspnoea

\section{$>$ Patients who were not willing to participate.}

$>$ Patients with very severe dyspnoea.

\section{DEVELOPMENT OF THE TOOL:}

Based on the exclusive review literature tool was prepared and validated by 6 nursing experts. A pilot study was feasible and reliable to conduct the main study. The tool mainly has two domains PART A: It deals with socio-demographic variables. It consists of 14 items like age in years, sex, education, occupation, marital status, place of residence, duration of illness, medical treatment, income per month, comorbid condition, smoking habits, years of smoking, exposure of allergens, and family history of COPD. PART B: Dyspnoea scale by Modified (UCSD) the University Of California, San Diego Shortness of Breath Questionnaire. These 15-items assess self-reported of shortness of breath while performing a variety of activities of daily living.

\section{DATA COLLECTION PROCEDURE:}

Demographic variable and the Modified University of California, San Diego Shortness of Breath Questionnaire were used to collect the data from subjects. The intervention was given in the form of pursed-lip breathing to COPD patients with frequency 5 minutes, 3 times a day for 5 days. 5 th-day evening post-test dyspnoea scores were assessed, Subjects were asked to follow pursed-lip breathing following all incidences of shortness of breath during their daily activities.

\section{FINDINGS:}

\section{DEMOGRAPHIC DATA}

The majority of participants involved in this research had the age range above 61 years and $30 \%$ in experimental and $41.25 \%$ in the control group respectively, and educational status most of the participants were gained primary and secondary schooling grades nearly $47.5 \%$ in both the groups. $53.75 \%$ were employed workers, closely $69 \%$ were married. $56.2 \%$ were residence of rural areas. $91.25 \%$ were suffering from a chronic obstructive pulmonary disease for 1-3 years, $43.75 \%$ were receiving regular treatment, and $52.50 \%$ receiving irregular treatment. In experimental (42.50\%) and control groups (31.25\%), monthly wages were reported above 15000 Indian rupees. the primary history of hypertension was $33.75 \%$ and smoking history was around $47.50 \%$. 
Table 1: Item wise distribution of Pre-test and post-test dyspnoea score among chronic obstructive pulmonary disease (COPD) patients in the experimental group.

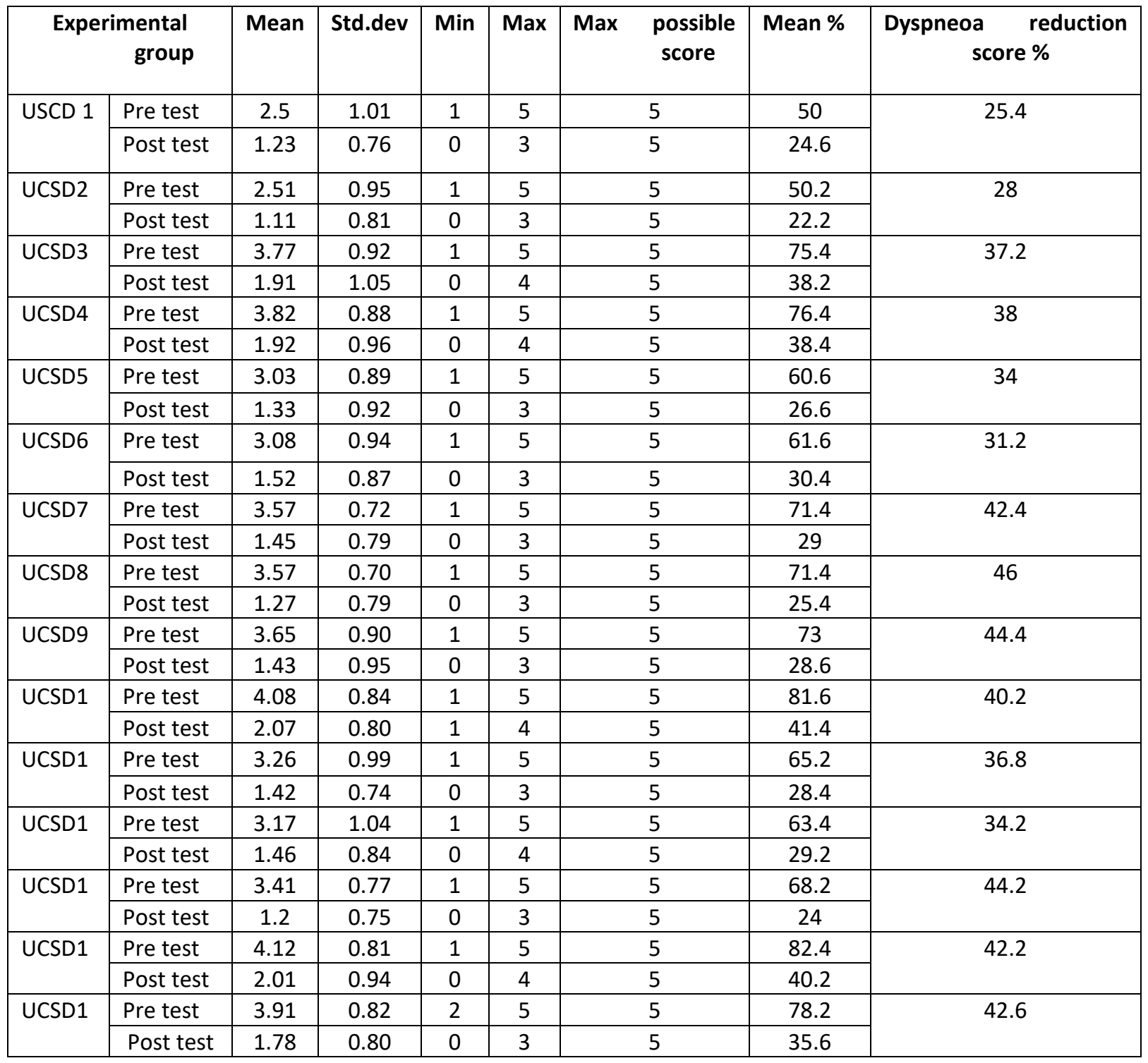

The data in Table 1 shows that in the experimental group, the mean percentage of pre and post-test dyspnoea scores were as follows at rest $50 \%$ in pre and $24.6 \%$ in the post test. The score was obtained $50.2 \%$ and $22.2 \%$ in pre and post while brushing the teeth. During walking the score were observed $75.4 \%$ and $38.2 \%$ in pre and post and in the same comparison between pre and post in different actions were documented as follow as while walking upstairs $76.4 \%$ and $38.4 \%$, while eating $60.6 \%$ and $26.6 \%$, standing up from a chair $61.6 \%$ and $30.4 \%$,bathing $71.4 \%$ and $29 \%$,dressing $71.4 \%$ and $25.4 \%$,during dishes $73 \%$ and $28.6 \%$,sweeping, cum vacuuming $81.6 \%$ and $41.4 \%$, making bed $65.2 \%$ and $28.4 \%$, shopping $63.4 \%$ and $29.2 \%$, while combing hair $68.2 \%$ and $24 \%$, while traveling $82.4 \%$ and $40.2 \%$, walking on a level of at your own pace $78.2 \%$ and $35.6 \%$.

In the control group, the mean percentage of pre and post-test dyspnoea scores were as follows at rest $53.4 \%$ in pre and $50 \%$ post-test. While brushing the teeth, $57.2 \%$ and $50 \%$,during walking $75.6 \%$ and $75.4 \%$, while walking upstairs $77 \%$ and $76.4 \%$, while eating $63.4 \%$ and $60.6 \%$, standing up from a chair $63.4 \%$ and $61.6 \%$,bathing $72.4 \%$ and $71.4 \%$,dressing $71.2 \%$ and $71 \%$,during dishes $72 \%$ and $70.6 \%$, sweeping, cum vacuuming $75.6 \%$ and $76.6 \%$, making bed $76 . \%$ and $75.2 \%$, shopping $67 \%$ and $65 \%$,while combing hair $67.4 \%$ and $65.2 \%$, while traveling $72.6 \%$ and $72.4 \%$, walking on a level of at your own pace $83 \%$ and $82.4 \%$. 
Table 2: item wise mean, SD, $t$ value score on the effectiveness of pursed-lip breathing on the level of dyspnoea among chronic obstructive pulmonary disease (COPD) patients in the experimental group.

\begin{tabular}{|c|c|c|c|c|c|c|c|c|c|}
\hline \multicolumn{2}{|c|}{ Experimental group } & \multirow{2}{*}{$\begin{array}{c}\text { Mean } \\
2.5 \\
\end{array}$} & \multirow{2}{*}{$\begin{array}{c}\text { SD.error } \\
0.11 \\
\end{array}$} & \multirow{2}{*}{$\begin{array}{c}\text { Std.dev } \\
1.01 \\
\end{array}$} & \multirow{3}{*}{$\begin{array}{c}\text { M.Diff } \\
1.26\end{array}$} & \multirow{3}{*}{$\begin{array}{c}\text { SE.Diff } \\
0.14\end{array}$} & \multirow{3}{*}{$\begin{array}{c}\text { SD Diff } \\
1.29\end{array}$} & \multirow{3}{*}{$\begin{array}{c}\text { t VALUE } \\
8.75\end{array}$} & \multirow{3}{*}{$\begin{array}{c}\text { P VALUE } \\
0.00\end{array}$} \\
\hline USCD 1 & Pre test & & & & & & & & \\
\hline & Post test & 1.23 & 0.08 & 0.76 & & & & & \\
\hline \multirow[t]{2}{*}{ UCSD2 } & Pre test & 2.51 & 0.10 & 0.95 & \multirow[t]{2}{*}{1.4} & \multirow[t]{2}{*}{0.14} & \multirow[t]{2}{*}{1.32} & \multirow[t]{2}{*}{9.43} & \multirow[t]{2}{*}{0.00} \\
\hline & Post test & 1.11 & 0.09 & 0.81 & & & & & \\
\hline \multirow[t]{2}{*}{ UCSD3 } & Pre test & 3.77 & 0.10 & 0.92 & \multirow[t]{2}{*}{1.86} & \multirow[t]{2}{*}{0.153} & \multirow[t]{2}{*}{1.37} & \multirow[t]{2}{*}{12.11} & \multirow[t]{2}{*}{0.00} \\
\hline & Post test & 1.91 & 0.11 & 1.05 & & & & & \\
\hline \multirow[t]{2}{*}{ UCSD4 } & Pre test & 3.82 & 0.09 & 0.88 & \multirow[t]{2}{*}{1.9} & \multirow[t]{2}{*}{0.151} & \multirow[t]{2}{*}{1.35} & \multirow[t]{2}{*}{12.53} & \multirow[t]{2}{*}{0.00} \\
\hline & Post test & 1.92 & 0.10 & 0.96 & & & & & \\
\hline \multirow[t]{2}{*}{ UCSD5 } & Pre test & 3.03 & 0.09 & 0.89 & \multirow[t]{2}{*}{1.7} & 0.156 & 1.39 & 10.86 & 0.00 \\
\hline & Post test & 1.33 & 0.10 & 0.92 & & & & & \\
\hline UCSD6 & Pre test & 3.08 & 0.10 & 0.94 & 1.56 & 0.13 & 1.22 & 11.45 & 0.00 \\
\hline & Post test & 1.52 & 0.09 & 0.87 & & & & & \\
\hline UCSD7 & Pre test & 3.57 & 0.08 & 0.72 & 2.125 & 0.11 & 1.07 & 17.73 & 0.00 \\
\hline & Post test & 1.45 & 0.08 & 0.79 & & & & & \\
\hline UCSD8 & Pre test & 3.57 & 0.07 & 0.70 & 2.3 & 0.11 & 1.011 & 20.34 & 0.00 \\
\hline & Post test & 1.27 & 0.08 & 0.79 & & & & & \\
\hline UCSD9 & Pre test & 3.65 & 0.10 & 0.90 & 2.21 & 0.149 & 1.33 & 14.79 & 0.00 \\
\hline & Post test & 1.43 & 0.10 & 0.95 & & & & & \\
\hline UCSD10 & Pre test & 4.08 & 0.09 & 0.84 & 2.01 & 0.133 & 1.19 & 15.0 & 0.00 \\
\hline & Post test & 2.07 & 0.09 & 0.80 & & & & & \\
\hline UCSD11 & Pre test & 3.26 & 0.11 & 0.99 & 1.83 & 0.14 & 1.29 & 12.67 & 0.00 \\
\hline & Post test & 1.42 & 0.08 & 0.74 & & & & & \\
\hline UCSD12 & Pre test & 3.17 & 0.11 & 1.04 & 1.71 & 0.15 & 1.41 & 10.81 & 0.00 \\
\hline & Post test & 1.46 & 0.09 & 0.84 & & & & & \\
\hline UCSD13 & Pre test & 3.41 & 0.08 & 0.77 & 2.21 & 0.11 & 0.98 & 19.99 & 0.00 \\
\hline & Post test & 1.2 & 0.08 & 0.75 & & & & & \\
\hline UCSD14 & Pre test & 4.12 & 0.09 & 0.81 & 2.11 & 0.14 & 1.30 & 14.50 & 0.00 \\
\hline & Post test & 2.01 & 0.10 & 0.94 & & & & & \\
\hline UCSD15 & Pre test & 3.91 & 0.09 & 0.82 & 2.16 & 0.13 & 1.22 & 15.76 & 0.00 \\
\hline & Post test & 1.78 & 0.09 & 0.80 & & & & & \\
\hline
\end{tabular}

Table 2 shows mean SD, difference, mean difference t value of the effectiveness of pursed-lip breathing on the level of dyspnoea among chronic obstructive pulmonary disease (COPD) patients in the experimental group. overall $p$-value score $(p<0.001)$ revealed highly significant differences in pre and post a comparison of all the items listed in the dyspnoea questionnaire in the experimental group and found no significant items to control group.

Nithyanada (2018) quasi-experimental non-equivalent control group design was used to assess the effectiveness of pursed-lip breathing exercises on dyspnoea among 60 COPD patients, the results show that, computed $t$ value highly significant $p<0.05$.there was a reduction in dyspnea score among the experimental group. 
Table 3: mean, mean percentage of pre-test and post-test dyspnoea scores of the experimental and control group.

\begin{tabular}{|c|c|c|c|c|c|c|c|}
\hline \multicolumn{2}{|c|}{ Dyspneoa score } & Min score & Max score & $\begin{array}{c}\text { Max } \\
\text { Possible } \\
\text { score }\end{array}$ & mean & Mean \% & $\begin{array}{l}\text { Dyspnoea } \\
\text { reduction } \\
\text { score }\end{array}$ \\
\hline $\begin{array}{c}\text { Experimental } \\
\text { group }\end{array}$ & Pre test & 16 & 75 & 75 & 51.45 & 68.6 & 37.79 \\
\cline { 2 - 8 } & Post test & 1 & 50 & 75 & 23.11 & 30.81 & \\
\hline \multirow{2}{*}{$\begin{array}{c}\text { Control } \\
\text { group }\end{array}$} & Pre test & 21 & 75 & 75 & 52.36 & 69.81 & 1.56 \\
\cline { 2 - 8 } & Post test & 16 & 75 & 75 & 51.19 & 68.25 & \\
\hline
\end{tabular}

\section{CONCLUSION}

There was a significant association between pre-test dyspnoea score and demographic variables such as (Pr0.002) marital status, duration of illness, ( $\operatorname{Pr} 0.000)$ comorbid condition (Pr0.004) and there was no significant association between other variables.

\section{RECOMMENDATION:}

The future research might be focused on with various domains, by using multiple standardized test tools with larger population and including all the types of patients with dyspnoea score, patients with COPD, and also the future study can be carried out including all the types of respiratory disease.

\section{REFERENCES:}

1. Brunner and Suddarth's.TextBook Of Medical and Surgical Nursing.13th Ed. Vol2. New Delhi: Wolters\& Kluwer Publications,India Pvt.Ltd;Philadelphia .2013: 571-580 - 1328.

2. Joyce M.Black,et.Al., Text Book Medical And Surgical Nursing Clinical Management For Positive Outcome..7 Edit.vol (2) Elsevier Publication, Missour I 2005:1760-1762.

3. Lewis SM, Heitkemper MC, Dirksen S. Medical-Surgical Nursing. 10th Ed. Missouri: Mosby Publication, India Pvt Ltd; 2011.. 141.

4. Polit F Denise,Cheryl TatanoBick. Nursing Research Principles and Methods 7th Ed. New Delhi: Lippincott Publications; Philadelphia.2014:P.289

5. Marylin E. Parker.Nursing Theories And Nursing Practice .2 Editions. F A Davis Company, Philadelphia 2006:235-243

6. Gosselink R. Controlled breathing and dyspnea in patients with chronic obstructive pulmonary disease (COPD). The Journal of Rehabilitation Research and Development. 2003; 40(5s):25.

7. Bender BG et.al. A Patient-Centered Walking Program for COPD Journal of Chronic Obstructive Pulmonary Disease.2016; 3(4):769-777.

8. Jean marigros. Grosbios JM .Long-term evaluation of home-based pulmonary rehabilitation in patients with COPD. International journal of chronic obstructive pulmonary disease. Volume 2015;10(1): 2037-2044

9. Jeongilkang. the effects of breathing exercises types on respiratory muscle activity and body function in patients with mild COPD.journal of physical therapy sciences.2016;28(2):500-505

10. Khajamohinuddin. Effect of PR in COPD patients to improve quality of life. international. journal of physiotherapy and research, 2014;Guntur.2(5):689-94.

11. Nield MA,et.al. Efficacy of pursed lips breathing: a breathing pattern retraining strategy for dyspnoea reduction. Cardiopulmonary Rehabilitation. 2017;27(4):237-44. 17.

12. O'Donnell DE, Webb KA.Exertional breathlessness in patients with chronic airflow limitation. The role of lung hyperinflation. Am Rev Respir Dis. 1993;148:1351-135

13. Siraj Ahmad.,et.,Assessment of dyspnoea and fatigue among COPD patients attending a tertiary care hospital in North India. International Journal of Advanced Research. 2016;3(6) 1436-1443 
14. Spruit MA, Singh SJ, Garvey C et.al. An official American thoracic society/European respiratory society statement: key concepts and advanced in pulmonary rehabilitation. AMJ respire crit care med 2013;188(8) 13-64

15. Global Initiative for Chronic Obstructive Lung Disease. Global strategy for the diagnosis management and prevention of Chronic Obstructive Pulmonary disease. Updated 2014. Global Initiative for Chronic Obstructive Lung Disease, 2014.

16. Prabu Rajkumar, Kamaraj Pattabi, Selvaraj Vadivoo, A cross-sectional study on the prevalence of chronic obstructive pulmonary disease (COPD) in India: rationale and methods BMJ Open. 2017;7(5): e15211

17. Nithyananda mogera, Asha Cynthia D .evaluate the effectiveness of pursed-lip breathing exercises on dyspnoea among chronic obstructive pulmonary disease (COPD) patients in selected hospitals of Mangalore .international journal of advanced science and research. 2018;3(2):55-60

18. World health organization: the burden of COPD. 